\title{
Genetic Variations within Metalloproteinases Impact on the Prophylaxis of Depressive Phases in Bipolar Patients
}

\author{
Antonio Drago a Barbara Monti ${ }^{b}$ Diana De Ronchi ${ }^{c}$ Alessandro Serretti ${ }^{c}$ \\ aIRCCS San Giovanni di Dio, Fatebenefratelli, Brescia, and Departments of ${ }^{b}$ Pharmacy and Biotechnologies and \\ 'Biomedical and Neuromotor Sciences, University of Bologna, Bologna, Italy
}

\section{Key Words}

Metalloproteinases · Bipolar disorder · Gene ·

Single-nucleotide polymorphism

\begin{abstract}
Background: The genetic background of the antidepressant response to pharmacological treatment in bipolar disorder (BD) remains elusive. This issue is of primary relevance in that the depressive phases of $\mathrm{BD}$ are difficult to treat and they are associated with suicide. Aim: We investigated the role of a set of genetic variations (single-nucleotide polymorphisms) harbored by matrix metalloproteinases (MMPs) as predictors of response to treatment in depressed BD patients. Methods: $654 \mathrm{BD}$ patients from the publicly available Systematic Treatment Enhancement Program for Bipolar Disorder study were investigated. The outcome was the number of depressive events corrected by the number of times patients were assessed. Clinical and sociodemographic variables were tested as possible stratification factors and included in the analysis if necessary. Genetic predictors were 43 SNPs harbored by 17 MMPs. Imputation, quality check and pruning were conducted according to standards. Results were corrected for multitesting. Results: rs486055 (MMP-10) was associated with the outcome. $T$ T homozygotes had $5.08 \pm 3.51$
\end{abstract}

events, CT had $3.47 \pm 3.18$ and CC had $2.57 \pm 2.96$ depressive events corrected for the times they had been assessed. The time during which $\mathrm{BD}$ patients were observed was not significantly different between the rs486055 genotypes. We found evidence that MMP-10 may be a mediator of the number of depressive phases during BD. Due to the limits of the study including the small-to-medium sample size, the naturalistic design and the possible occurrence of false-positive findings, independent analyses are warranted.

(c) 2014 S. Karger AG, Basel

\section{Introduction}

Metalloproteinases as Candidates for Bipolar Disorder Matrix metalloproteinases (MMPs) are key enzymes to the extracellular matrix (ECM) that remodel the pericellular environment. Their activity is pivotal to the communication between cells, and it is central to the orchestration of the activity of the central nervous system [1]. MMPs are activated after the disruption of an interaction between a cysteine residue and the $\mathrm{Zn}^{2+}$ ion in their catalytic site. Organomercurial compounds, heavy metals, denaturating agents or oxidants and proteases can disrupt this interaction and activate the MMPs

\section{KARGER}

E-Mail karger@karger.com

www.karger.com/nps
(C) 2014 S. Karger AG, Basel

0302-282X/14/0692-0076\$39.50/0
Dr. Antonio Drago

Institute of Psychiatry, University of Bologna

Viale Carlo Pepoli 5

IT-40123 Bologna (Italy)

E-Mail antonio.drago@unibo.it 
[2]. The expression of MMPs is enhanced during many physiological conditions including wound healing, ovulation, blastocyst implantation, bone growth and angiogenesis. Inflammatory events enhance the expression of MMPs, and their activity is enhanced in many pathophysiological conditions including tumor invasion, rheumatoid arthritis, periodontal disease and atherosclerosis. The activity of MMPs increases also during blood-brain barrier dysfunction, demyelination, neuroinflammation and neurotoxicity. Consistently, MMPs are involved in a list of neurological diseases including multiple sclerosis, amyotrophic lateral sclerosis, Alzheimer's and Parkinson's diseases [1, 3, 4]. In particular, many ECM proteins, adhesion molecules, chemokines, receptors and growth factors interact during neuronal migration, survival, synaptogenesis and plasticity. Thus, ECMs may be good candidates in the investigation of the diseases of the central nervous system, including bipolar disorder (BD). BD is a complex and frequent ( $1 \%$ prevalence worldwide, which rises up to $6.4 \%$ when subthreshold cases are included [5]) neurological disease characterized by pathological mood swings, which results in tremendous social costs [6, 7]. Its biological causes are incompletely understood. As a consequence, the current pharmacological treatments do not target its molecular core and are only partially effective $[7,8]$. The identification of the genetic causes of BD could pave the way to the synthesis of new and more efficacious compounds, and some lines of evidence stress the role of MMPs in BD: Rybakowski et al. [9] recently reported that MMP-9 serum levels were increased in a sample of 54 inpatients with BD (19 males, 35 females), aged $42 \pm 14$ years, compared to 29 subjects (15 males, 14 females), aged $40 \pm 11$ years, as a control group. Moreover, MMP-9 serum levels significantly correlated with the depressive phases in younger subjects $(<45$ years). The same group could not show a genetic impact of a variant - the $-1562 \mathrm{C} / \mathrm{T}$ MMP-9 gene polymorphism (rs3918242) - towards lithium prophylaxis in a sample of 109 BD patients [10]. In a previous study, the same group identified an impact of MMP-9 towards cognition in BD patients [11]. Nevertheless, conflicting results from other research groups that also focused on the possible role of MMPs in BD can be found [12], and the small sample size and the incomplete genetic coverage decreased the power of the studies that retrieved positive association findings. Thus, further studies are needed. In the present work, we extended the analysis of the genetic impact of a list of MMPs towards depressive phases of BD patients.

Genetic Variations within

Metalloproteinases in BD

\section{Methods}

\section{Sample under Investigation}

The sample under investigation was retrieved from the publicly available Systematic Treatment Enhancement Program for Bipolar Disorder (STEP-BD) [13]. During the study, BD patients of every subtype with ages $\geq 15$ years were entered into a study registry. All patients received a systematic assessment battery at entry and were treated by a psychiatrist using a series of model practice procedures consistent with expert recommendations. At every follow-up visit, the treating psychiatrist completed a standardized assessment and assigned an operationalized clinical status based on DSM-IV criteria. Patients had independent evaluations at regular intervals throughout the study and remained under the care of the same treating psychiatrist while making transitions between randomized care studies and the standard care treatment pathways. In the present study, we only considered records from the naturalistic first phase of the study. Table 1 reports the characteristics of the sample under analysis. BD I and BD II patients were all included in the analysis to increase the power of the study. No differentiation between BD I and BD II could be made due to the lack of data (number of manic and hypomanic phases in the past). This may be considered as a limitation of the study. Nevertheless, major depressive episodes are common traits between BD I and BD II patients, which offers a rationale to include all the patients in the same genetic association study when investigating depressive phases.

\section{Definition of the Phenotype}

The ratio between the times patients were found to be definitively depressed and the times patients were observed during the phase of the study under analysis was the outcome of choice. The correlations between the phenotype of choice and a set of other phenotypes calculated at standard time points (number of depressive phases from 30, 90, 120 and so forth days from the beginning of the study) - a more classical approach to this kind of studies were calculated. We had confirmation that the phenotype under analysis significantly correlated with almost all the phenotypes at different time points, with the advantage of having $0 \%$ of missing values. Results are reported in table 2 . The only time point at which the correlation was not significant was after 30 days from the beginning of the study. Nevertheless, the number of missing information for this time point (94\%) may be held accountable for the lack of association. All patients were treated in a naturalistic environment according to the international guidelines for the treatment of BD. Thus, the authors interpreted the phenotype under analysis as a measure of the efficacy of the pharmacological treatments administered to patients. This phenotype could also be related to depressive phases per se, rather than to the impact of the pharmacological treatments. The genetic effect could then be related to the course of disease rather than to the impact of the pharmacological treatments.

\section{Study of Stratification Factors}

The sociodemographic and clinical variables were investigated as possible stratification factors. A story of treatment for alcoholrelated problems was found to be significantly associated with the outcome as was included in the analysis. Treatment (combination of treatments) correlated with the number of depressive episodes during the period of observation and was included in the analysis. 
Table 1. Sample description

\begin{tabular}{|c|c|c|}
\hline Variable & Result & Association with outcome \\
\hline Age & $41.48 \pm 12.6$ years & $\mathrm{t}=-0.6241$, d.f. $=652, \mathrm{p}$ value $=0.5328$ \\
\hline Gender & $\begin{array}{l}\text { female }=353(54 \%) \\
\text { male }=300(45.9 \%) \\
\text { transgender }=1(0.2 \%)\end{array}$ & $f=0.08$, d.f. $=2, p$ value $=0.923$ \\
\hline Ethnicity & $\begin{array}{l}\text { Asian or Pacific Islander }=0(0 \%) \\
\text { Black or African-American }=0(0 \%) \\
\text { Native American, Eskimo or Aleut }=0(0 \%) \\
\text { no primary race }=0(0 \%) \\
\text { other, specify }=0(0 \%) \\
\text { White or Caucasian }=654(100 \%)\end{array}$ & not calculable \\
\hline Diagnosis & $\mathrm{BD}=654(100 \%)$ & not calculable \\
\hline $\begin{array}{l}\text { Times depressed/ } \\
\text { times seen }\end{array}$ & $2.86 \pm 3.06$ & \\
\hline $\begin{array}{l}\text { Past treatment for } \\
\text { alcohol-related } \\
\text { problems }\end{array}$ & $\begin{array}{l}\text { not available }=43(6.6 \%) \\
\text { no }=244(37.3 \%) \\
\text { not on original } \\
\text { form }=266(40.7 \%) \\
\text { unknown }=26(4 \%) \\
\text { yes }=75(11.5 \%)\end{array}$ & $\mathrm{f}=2.54$, d.f. $=4, \mathrm{p}$ value $=0.038$ \\
\hline
\end{tabular}

Table 3 reports the details of the treatments delivered to subjects under analysis during phase 1 of the study. The higher the number of depressive events during the period of observation, the higher the rate of administration of a combination of treatments with antipsychotics, mood stabilizers and antidepressants. The administration of an antidepressant alone did not correlate with the number of depressive events, consistent with the literature and guidelines in the field.

\section{Power of the Study}

We had sufficient power $(0.80)$ to detect a small-to-medium effect size (0.22) between two allelic frequencies, each represented by at least 300 subjects (R-cran pwr package used for the analysis).

\section{Selection of Genes}

Genes that belong to the MMP family that were used for the analysis are reported in table 4. Imputation was run for the genes that belong to the pathway under analysis in order to decrease the computational effort. The CEU HapMap 1,000 genomes served for the analysis. From the original (not pruned) set of 203 single-nucleotide polymorphisms from the pathway under analysis we obtained 43 that passed the imputation quality control (info $>0.9$ ) and the pruning $\left(\mathrm{r}^{2}>0.2\right)$. Pruning was undertaken after imputation.

\section{Statistical Methods}

Covariate linear regression was the statistical model for the analysis. PLINK was used for the analysis [14]. The $p$ value for a significant result was set at $0.05 / 43=0.001$ (Bonferroni correction).

\section{Results}

rs486055 in the $M M P 10$ gene was found associated with the number of depressive events corrected for the number of total visits during the period of observation $(p=0.0004$; $\mathrm{t}=3.68)$. In particular, TT homozygotes $(\mathrm{n}=10) \mathrm{had}$ $5.08 \pm 3.51$ events, CT $(n=131)$ had $3.47 \pm 3.18$ and CC $(\mathrm{n}=359)$ had $2.57 \pm 2.96$ depressive events corrected for times they had been assessed during the period of observation (Hardy-Weinberg equilibrium, $\mathrm{p}=0.58$ ). The time during which BD patients were observed during the period included in the analysis was not significantly different between the rs486055 genotypes ( $\mathrm{TT}=15 \pm 10.28$; CT $=$ $20.49 \pm 13.47 ; \mathrm{CC}=17.98 \pm 13.57 ; \mathrm{t}=1.18 ; \mathrm{p}=0.23)$.

\section{Discussion}

We found evidence that the rs486055 C/T nonsynonymous (R53K) exonic variant in MMP-10 impacts on the number of depressive events during BD. The implication of this extracellular enzyme in response to treatment during bipolar depression is new in the literature. In the brain, MMPs comprise a family of over 20 endo- 
Table 2. Analysis of the correlation between the number of depressive events per unit visit and the number of depressive events per defined time points

\begin{tabular}{|c|c|c|c|c|c|c|c|c|}
\hline $\begin{array}{l}\text { Days from } \\
\text { baseline }\end{array}$ & $\begin{array}{l}\text { Mean depressive } \\
\text { events per time }\end{array}$ & Missing, \% & $\begin{array}{l}\text { Mean depressive } \\
\text { events per visit unit }\end{array}$ & $\begin{array}{l}\text { Pearson correlation } \\
\text { coefficient }\end{array}$ & $\mathrm{t}$ & $\mathrm{p}$ & conf1 & conf2 \\
\hline 30 & $1.24 \pm 0.51$ & 94.22 & $2.26 \pm 2.92$ & 0.1 & 0.87 & 0.39 & -0.13 & 0.32 \\
\hline 90 & $1.48 \pm 0.98$ & 83.72 & $2.26 \pm 2.92$ & 0.3 & 5.4 & 0.0000001 & 0.19 & 0.4 \\
\hline 120 & $1.61 \pm 1.14$ & 78.61 & $2.26 \pm 2.92$ & 0.4 & 8.63 & $<0.0000001$ & 0.32 & 0.48 \\
\hline 150 & $1.68 \pm 1.17$ & 74.40 & $2.26 \pm 2.92$ & 0.48 & 11.48 & $<0.0000001$ & 0.4 & 0.54 \\
\hline 240 & $1.95 \pm 1.42$ & 62.90 & $2.26 \pm 2.92$ & 0.62 & 18.97 & $<0.0000001$ & 0.57 & 0.67 \\
\hline 270 & $2.03 \pm 1.46$ & 59.52 & $2.26 \pm 2.92$ & 0.65 & 20.76 & $<0.0000001$ & 0.6 & 0.69 \\
\hline 300 & $2.13 \pm 1.53$ & 55.98 & $2.26 \pm 2.92$ & 0.68 & 23.26 & $<0.0000001$ & 0.64 & 0.72 \\
\hline 330 & $2.18 \pm 1.58$ & 52.82 & $2.26 \pm 2.92$ & 0.68 & 23.85 & $<0.0000001$ & 0.64 & 0.72 \\
\hline 360 & $2.22 \pm 1.63$ & 49.97 & $2.26 \pm 2.92$ & 0.69 & 24.25 & $<0.0000001$ & 0.64 & 0.72 \\
\hline 390 & $2.27 \pm 1.66$ & 47.03 & $2.26 \pm 2.92$ & 0.69 & 25.08 & $<0.0000001$ & 0.65 & 0.73 \\
\hline 540 & $2.49 \pm 1.85$ & 34.88 & $2.26 \pm 2.92$ & 0.75 & 30.68 & $<0.0000001$ & 0.71 & 0.78 \\
\hline 570 & $2.54 \pm 1.89$ & 32.49 & $2.26 \pm 2.92$ & 0.76 & 32.59 & $<0.0000001$ & 0.73 & 0.79 \\
\hline 600 & $2.58 \pm 1.94$ & 30.47 & $2.26 \pm 2.92$ & 0.78 & 34.37 & $<0.0000001$ & 0.75 & 0.8 \\
\hline 630 & $2.63 \pm 1.99$ & 28.43 & $2.26 \pm 2.92$ & 0.79 & 35.64 & $<0.0000001$ & 0.76 & 0.81 \\
\hline 660 & $2.68 \pm 2.04$ & 26.59 & $2.26 \pm 2.92$ & 0.79 & 35.95 & $<0.0000001$ & 0.76 & 0.81 \\
\hline 690 & $2.71 \pm 2.05$ & 24.91 & $2.26 \pm 2.92$ & 0.8 & 37.3 & $<0.0000001$ & 0.77 & 0.82 \\
\hline 720 & $2.74 \pm 2.07$ & 23.29 & $2.26 \pm 2.92$ & 0.81 & 39.17 & $<0.0000001$ & 0.79 & 0.83 \\
\hline 750 & $2.77 \pm 2.1$ & 21.52 & $2.26 \pm 2.92$ & 0.82 & 41.07 & $<0.0000001$ & 0.8 & 0.84 \\
\hline 780 & $2.81 \pm 2.12$ & 20.03 & $2.26 \pm 2.92$ & 0.83 & 42.78 & $<0.0000001$ & 0.81 & 0.85 \\
\hline 810 & $2.84 \pm 2.14$ & 18.71 & $2.26 \pm 2.92$ & 0.85 & 44.97 & $<0.0000001$ & 0.82 & 0.86 \\
\hline 840 & $2.86 \pm 2.16$ & 17.34 & $2.26 \pm 2.92$ & 0.85 & 45.75 & $<0.0000001$ & 0.83 & 0.87 \\
\hline 870 & $2.89 \pm 2.2$ & 16.12 & $2.26 \pm 2.92$ & 0.86 & 47.32 & $<0.0000001$ & 0.84 & 0.87 \\
\hline
\end{tabular}

Missing: percentage of subjects that lack the investigated value at a certain time point; conf1 = upper confidence limit; conf $2=$ lower confidence limit.

Table 3. Combination of drug classes during the period of observation and correlation with the outcome

\begin{tabular}{lccll}
\hline Drug & Total & Dep. & Nondep. & Association with depressive events \\
\hline 0/0/ad & $22.42 \pm 115$ & $23.01 \pm 115.74$ & $21.98 \pm 114.49$ & $\mathrm{~F}=2.019 ; \mathrm{p}=0.156$ \\
0/ap/0 & $29.7 \pm 137.62$ & $25.99 \pm 127.57$ & $32.46 \pm 144.61$ & $\mathrm{~F}=2.48 ; \mathrm{p}=0.116$ \\
0/ap/ad & $16.03 \pm 96.29$ & $17.33 \pm 103.11$ & $15.07 \pm 90.91$ & $F=18.28 ; p=2.07 e-05$ \\
st/0/0 & $379.93 \pm 404.28$ & $367.79 \pm 405.49$ & $388.95 \pm 403.25$ & $\mathrm{~F}=5.688 ; \mathrm{p}=0.0172$ \\
st/0/ad & $218.06 \pm 344.87$ & $225.72 \pm 350.47$ & $212.38 \pm 340.64$ & $F=39.82 ; p=4.07 e-10$ \\
st/ap/0 & $180.55 \pm 311.57$ & $179.7 \pm 315.06$ & $181.18 \pm 309.04$ & $F=26.72 ; p=2.8 e-07$ \\
st/ap/ad & $97.83 \pm 240.76$ & $105.28 \pm 248.1$ & $92.3 \pm 235.07$ & $F=28.2 ; p=1.33 e-07$ \\
\hline
\end{tabular}

0 = No drug; ad = antidepressants; ap = antipsychotics; st = mood stabilizers; dep. $=$ administered during depression; nondep.$=$ ad ministered outside depressive phases. Association: statistics of the association between the number of depressive events per visit unit and the kind of treatment administered to subjects. Any combinations that included antidepressants but not antidepressants alone were significantly (italicized in the table) associated with the number of depressive events per visit unit.

Genetic Variations within

Metalloproteinases in BD
Neuropsychobiology 2014;69:76-82 DOI: $10.1159 / 000356971$ 
Table 4. Genes and single-nucleotide polymorphisms (SNPs) under analysis

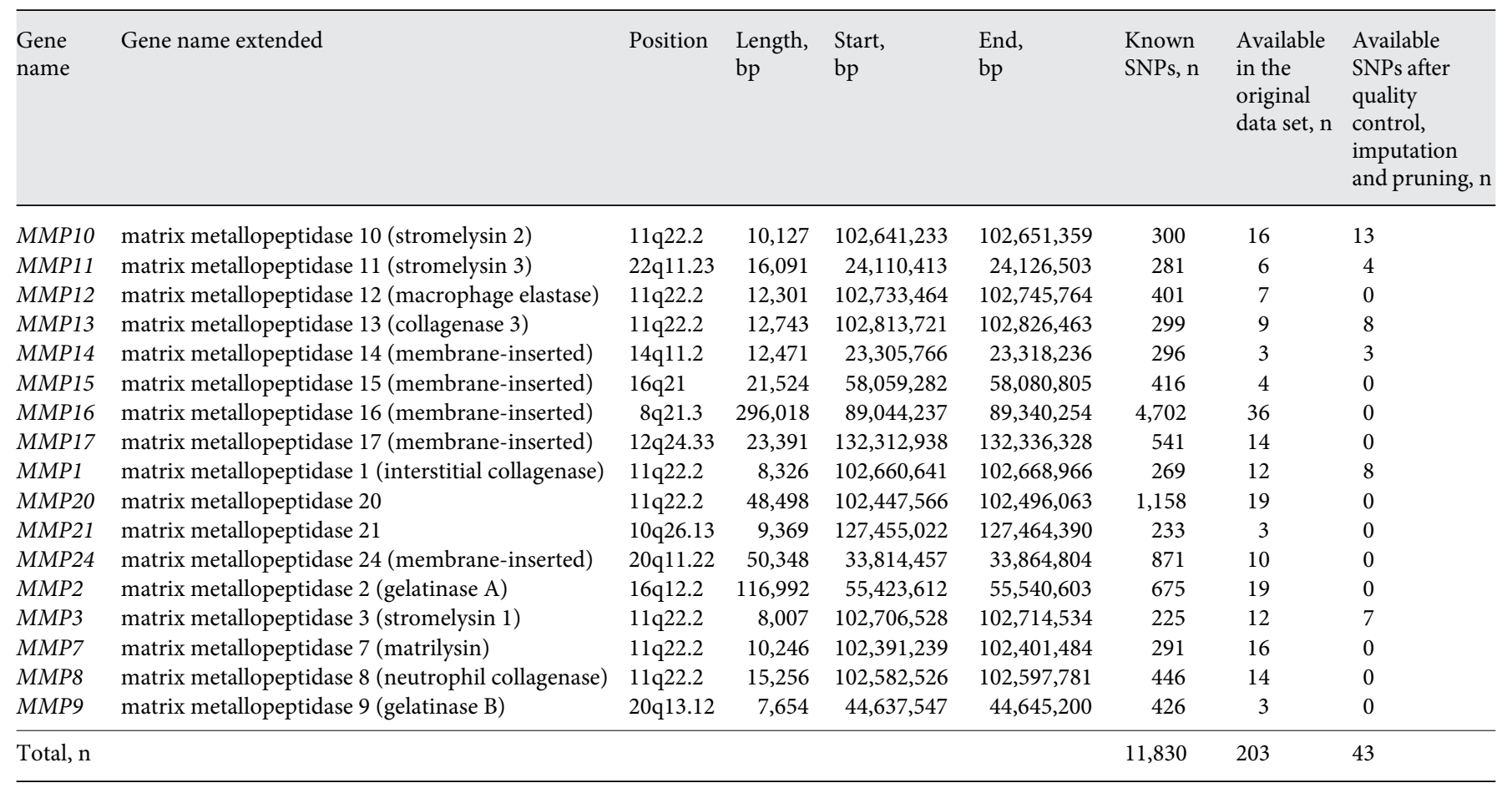

$\mathrm{bp}=$ Base pairs.

peptidases synthesized and secreted by both neuronal and glial cells. These enzymes serve as effectors of many brain cellular functions, such as migration, cytotoxicity, tissue remodeling, cell behavior and cell-cell communication via degradation of ECM components. In particular, they play a critical role in the degradation and/or proteolytic processing of many ECM factors, including growth factors, cytokines, chemokines, adhesion molecules and other proteins of the cell surface, proteases, intercellular junction proteins and structural molecules. Moreover, MMPs have been implicated in numerous neurological diseases, including multiple sclerosis, amyotrophic lateral sclerosis and other neuromuscular diseases, neurodegenerative diseases, such as Alzheimer's disease and Huntington's disease, as well as epilepsy, addiction, fragile-X syndrome and autism [15-23]. The association of a polymorphism in an $M M P$ gene and the $\mathrm{BD}$ is not surprising, as it has been previously demonstrated that the functional $-1562 \mathrm{C} / \mathrm{T}$ polymorphism of the MMP9 gene segregates in BD [24]. Moreover, a polymorphism in $M M P 9$ was associated with schizophrenia, suggesting that the MMP9 gene may be a common susceptibility gene to major psychoses [25], further supporting the overlap between the genetic loci and alleles that predispose to these disorders $[26,27]$. While the role of many MMPs, including MMP-2, MMP-3, MMP-7 and especially MMP-9, in synaptic plasticity, remodeling and spine morphology is well established [28-36], and their alteration is known to be associated with neuropathological and psychiatric conditions [22, 32, 33, 37, 38], MMP-10 has never been correlated before either with brain plasticity or with neuropathologies. On the other hand, MMP-10 is known to be upregulated in brain tumors $[39,40]$, ischemic neurons after stroke $[41,42]$ and cerebrospinal fluid of cerebral adrenoleukodystrophy [43], sustaining the role of this MMP in neurodegeneration. In agreement with that, a role of MMP-10 has been demonstrated in Huntington's disease, as MMP-10 is involved in the pathological cleavage of hungtingtin, leading to the production of toxic huntingtin fragments in striatal neurons [19]. However, considering that there are now many lines of evidence showing that synaptic plasticity is dysfunctional in BD $[44,45]$ and that MMPs, including MMP-10, are involved in the tiny regulated proteolysis of many ECM substrates involved in synaptic plasticity, it is tempting to speculate that the correlation between the MMP-10 exonic variants and the number of depressive events could be related to the possible role of 
MMP-10 in brain plasticity, through proteolysis of the ECM proteins involved in neurotransmission between neurons or between neurons and glial cells. In particular, the contribution of MMP-10 to brain inflammation, which is mainly related to the activity of the glial cells [46-48], and the relevance of neuroinflammation in BD [49-51], leads to a possible hypothesis of an MMP-10-related imbalance in neuron-glia interactions in synaptic plasticity alteration in BD somehow linked to neuroinflammation.

The present study is limited by the small-to-medium sample size that may have decreased the power of the study to the point that small but true genetic effects went undetected. To limit this caveat we designed a specific output for the analysis in order to enroll as many patients as possible. The demonstration that this outcome was significantly correlated with a number of other possible outcomes calculated with more classical methods, confirmed the validity of our analysis. Nevertheless, more independent studies are needed to confirm the role of rs 486055 in shaping the risk of a nonresponse to common pharmacological treatments during the depressive phases of $\mathrm{BD}$. Another possible limit of the study depends on the naturalistic design of the STEP-BD study. We could only control statistically for this caveat. Moreover, a higher external validity versus a lower internal validity is a classical advantage of a naturalistic design. For a more thorough analysis of this relevant methodological issue, please refer to Tunis et al. [52]. Our findings should be considered as suggestive, waiting for a confirmation by a more strict and classic pharmacogenetic approach. Finally, this kind of investigations is biased towards false-positive findings
[53]. We tried to face this limit by applying a strict threshold. Nevertheless, this approach, despite being statistically sound, may be ineffective concerning the true biological correlations.

\section{Acknowledgments}

We thank the National Institute of Mental Health (NIMH) for having had the possibility to analyze their data on the STEP-BD sample. We also thank the authors of previous publications of this data set, and foremost we thank the patients and their families who accepted to be enrolled in the study. Data and biomaterials were collected for the STEP-BD, a multicenter, longitudinal (5- to 8 -year) project selected from responses to RFP No. NIMH-98DS-0001, 'Treatment for Bipolar Disorder'. The project was led by Gary Sachs, MD, and coordinated by the Massachusetts General Hospital in Boston, Mass., USA. The NIMH grant number was 2N01MH080001-001. Given the major public health implications of identifying genes responsible for severe neuropsychiatric disorders, the NIMH has funded a Human Genetics Initiative. The goal of this initiative is to establish a national resource of clinical data and biomaterials that are collected from individuals with Alzheimer's disease, schizophrenia or bipolar I disorder, in order to aid researchers in understanding the genetic bases of these disorders. The NIMH Bipolar Disorder Genetics Initiative is supported by the Office of Human Genetics and Genomic Resources in NIMH's Division of Neuroscience and Basic Behavioral Science. Since 1996, data and biomaterials (cell lines and DNA samples) have been available to qualified investigators who study the genetics of $\mathrm{BP}$ and may be accessed by following a set of instructions.

\section{Disclosure Statement}

The authors declare no conflicts of interest.

\section{References}

$\checkmark 1$ Van Hove I, Lemmens K, Van de Velde S, Verslegers M, Moons L: Matrix metalloproteinase- 3 in the central nervous system: a look on the bright side. J Neurochem 2012;123: 203-216.

2 Van Wart HE, Birkedal-Hansen H: The cysteine switch: a principle of regulation of metalloproteinase activity with potential applicability to the entire matrix metalloproteinase gene family. Proc Natl Acad Sci USA 1990;87: 5578-5582.

3 Wetzel M, Li L, Harms KM, Roitbak T, Ventura PB, Rosenberg GA, et al: Tissue inhibitor of metalloproteinases-3 facilitates Fas-mediated neuronal cell death following mild ischemia. Cell Death Differ 2008;15:143-151.

4 Rosenberg GA: Matrix metalloproteinases and their multiple roles in neurodegenerative diseases. Lancet Neurol 2009;8:205-216.
5 Judd LL, Akiskal HS: The prevalence and disability of bipolar spectrum disorders in the US population: re-analysis of the ECA database taking into account subthreshold cases. J Affect Disord 2003;73:123-131.

6 Kleinman L, Lowin A, Flood E, Gandhi G, Edgell E, Revicki D: Costs of bipolar disorder. Pharmacoeconomics 2003;21:601-622.

7 Sidor MM, MacQueen GM: An update on antidepressant use in bipolar depression. Curr Psychiatry Rep 2012;14:696-704.

8 Popovic D, Reinares M, Goikolea JM, Bonnin CM, Gonzalez-Pinto A, Vieta E: Polarity index of pharmacological agents used for maintenance treatment of bipolar disorder. Eur Neuropsychopharmacol 2012;22:339-346.

-9 Rybakowski JK, Remlinger-Molenda A, CzechKucharska A, Wojcicka M, Michalak M, Losy J: Increased serum matrix metalloproteinase-9
(MMP-9) levels in young patients during bipolar depression. J Affect Disord 2013;146:286-289.

10 Rybakowski JK, Skibinska M, Suwalska A, Leszczynska-Rodziewicz A, Kaczmarek L, Hauser J: Functional polymorphism of matrix metalloproteinase-9 (MMP-9) gene and response to lithium prophylaxis in bipolar patients. Hum Psychopharmacol 2011;26:168171.

11 Rybakowski JK, Skibinska M, LeszczynskaRodziewicz A, Kaczmarek L, Hauser J: Matrix metalloproteinase-9 gene modulates prefrontal cognition in bipolar men. Psychiatr Genet 2009;19:108-109.

12 Kucukali CI, Aydin M, Ozkok E, Bilge E, Orhan $\mathrm{N}$, Zengin A, et al: Do schizophrenia and bipolar disorders share a common disease susceptibility variant at the MMP3 gene? Prog Neuropsychopharmacol Biol Psychiatry 2009;33:557-561.
Genetic Variations within

Metalloproteinases in BD
Neuropsychobiology 2014;69:76-82 DOI: $10.1159 / 000356971$ 


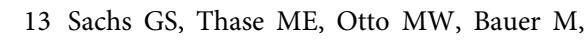
Miklowitz D, Wisniewski SR, et al: Rationale, design, and methods of the Systematic Treatment Enhancement Program for Bipolar Disorder (STEP-BD). Biol Psychiatry 2003;53: 1028-1042.

14 Purcell S, Neale B, Todd-Brown K, Thomas L, Ferreira MAR, Bender D, et al: PLINK: a tool set for whole-genome association and population-based linkage analyses. Am J Hum Genet 2007;81:559-575.

15 Leppert D, Lindberg RL, Kappos L, Leib SL: Matrix metalloproteinases: multifunctional effectors of inflammation in multiple sclerosis and bacterial meningitis. Brain Res Brain Res Rev 2001;36:249-257.

16 Renaud S, Leppert D: Matrix metalloproteinases in neuromuscular disease. Muscle Nerve 2007;36:1-13.

$\checkmark 17$ Blobel CP: Remarkable roles of proteolysis on and beyond the cell surface. Curr Opin Cell Biol 2000;12:606-612.

-18 Duran-Vilaregut J, del Valle J, Manich G, Camins A, Pallàs M, Vilaplana J, et al: Role of matrix metalloproteinase-9 (MMP-9) in striatal blood-brain barrier disruption in a 3-nitropropionic acid model of Huntington's disease. Neuropathol Appl Neurobiol 2011;37:525-537.

$\checkmark 19$ Miller JP, Holcomb J, Al-Ramahi I, de Haro M, Gafni J, Zhang N, et al: Matrix metalloproteinases are modifiers of huntingtin proteolysis and toxicity in Huntington's disease. Neuron 2010;67:199-212.

-20 Takács E, Nyilas R, Szepesi Z, Baracskay P, Karlsen B, Røsvold T, et al: Matrix metalloproteinase- 9 activity increased by two different types of epileptic seizures that do not induce neuronal death: a possible role in homeostatic synaptic plasticity. Neurochem Int 2010;56:799-809.

-21 Wang LW, Berry-Kravis E, Hagerman RJ: Fragile X: leading the way for targeted treatments in autism. Neurother J Am Soc Exp Neurother 2010;7:264-274.

22 Brown TE, Forquer MR, Cocking DL, Jansen HT, Harding JW, Sorg BA: Role of matrix metalloproteinases in the acquisition and reconsolidation of cocaine-induced conditioned place preference. Learn Mem 2007;14:214-223.

-23 Nakamoto K, Kawasaki S, Kobori T, FujitaHamabe W, Mizoguchi H, Yamada K, et al: Involvement of matrix metalloproteinase-9 in the development of morphine tolerance. Eur J Pharmacol 2012;683:86-92.

-24 Rybakowski JK, Skibinska M, LeszczynskaRodziewicz A, Kaczmarek L, Hauser J: Matrix metalloproteinase-9 gene and bipolar mood disorder. Neuromolecular Med 2009;11:128132.

25 Rybakowski JK, Skibinska M, Kapelski P, Kaczmarek L, Hauser J: Functional polymorphism of the matrix metalloproteinase-9 (MMP-9) gene in schizophrenia. Schizophr Res 2009;109:90-93.

26 Carroll LS, Owen MJ: Genetic overlap between autism, schizophrenia and bipolar disorder. Genome Med 2009;1:102.
27 Benekareddy M, Mehrotra P, Kulkarni VA, Ramakrishnan P, Dias BG, Vaidya VA: Antidepressant treatments regulate matrix metalloproteinases-2 and -9 (MMP-2/MMP-9) and tissue inhibitors of the metalloproteinases (TIMPS 1-4) in the adult rat hippocampus. Synapse 2008;62:590-600.

28 Szklarczyk A, Lapinska J, Rylski M, McKay RDG, Kaczmarek L: Matrix metalloproteinase-9 undergoes expression and activation during dendritic remodeling in adult hippocampus. J Neurosci Off J Soc Neurosci 2002; 22:920-930.

29 Meighan SE, Meighan PC, Choudhury P, Davis CJ, Olson ML, Zornes PA, et al: Effects of extracellular matrix-degrading proteases matrix metalloproteinases 3 and 9 on spatial learning and synaptic plasticity. J Neurochem 2006;96:1227-1241.

30 Nagy V, Bozdagi O, Matynia A, Balcerzyk M, Okulski P, Dzwonek J, et al: Matrix metalloproteinase- 9 is required for hippocampal latephase long-term potentiation and memory. J Neurosci Off J Soc Neurosci 2006;26:19231934.

31 Bilousova TV, Rusakov DA, Ethell DW, Ethell IM: Matrix metalloproteinase-7 disrupts dendritic spines in hippocampal neurons through NMDA receptor activation. J Neurochem 2006;97:44-56.

32 Falo MC, Fillmore HL, Reeves TM, Phillips LL: Matrix metalloproteinase-3 expression profile differentiates adaptive and maladaptive synaptic plasticity induced by traumatic brain injury. J Neurosci Res 2006;84:768-781.

33 Jovanova-Nesic K, Shoenfeld Y: MMP-2, VCAM-1 and NCAM-1 expression in the brain of rats with experimental autoimmune encephalomyelitis as a trigger mechanism for synaptic plasticity and pathology. J Neuroimmunol 2006;181:112-121.

34 Okulski P, Jay TM, Jaworski J, Duniec K, Dzwonek J, Konopacki FA, et al: TIMP-1 abolishes MMP-9-dependent long-lasting longterm potentiation in the prefrontal cortex. Biol Psychiatry 2007;62:359-362.

-35 Nagy V, Bozdagi O, Huntley GW: The extracellular protease matrix metalloproteinase- 9 is activated by inhibitory avoidance learning and required for long-term memory. Learn Mem 2007;14:655-664.

36 Michaluk P, Wawrzyniak M, Alot P, Szczot M, Wyrembek P, Mercik K, et al: Influence of matrix metalloproteinase MMP-9 on dendritic spine morphology. J Cell Sci 2011;124: 3369-3380.

37 Wilczynski GM, Konopacki FA, Wilczek E, Lasiecka Z, Gorlewicz A, Michaluk P, et al: Important role of matrix metalloproteinase 9 in epileptogenesis.JCell Biol2008;180:1021-1035.

38 Mizoguchi H, Nakade J, Tachibana M, Ibi D, Someya E, Koike H, et al: Matrix metalloproteinase-9 contributes to kindled seizure development in pentylenetetrazole-treated mice by converting pro-BDNF to mature BDNF in the hippocampus. J Neurosci 2011; 31:12963-12971.
39 Bodey B, Bodey B Jr, Siegel SE, Kaiser HE: Matrix metalloproteinase expression in childhood astrocytomas. Anticancer Res 2000;20: 3287-3292.

40 Thorns V, Walter GF, Thorns C: Expression of MMP-2, MMP-7, MMP-9, MMP-10 and MMP-11 in human astrocytic and oligodendroglial gliomas. Anticancer Res 2003;23: 3937-3944.

-41 Cuadrado E, Rosell A, Penalba A, Slevin M, Alvarez-Sabín J, Ortega-Aznar A, et al: Vascular MMP-9/TIMP-2 and neuronal MMP-10 up-regulation in human brain after stroke: a combined laser microdissection and protein array study. J Proteome Res 2009;8:3191-3197.

42 Orbe J, Barrenetxe J, Rodriguez JA, Vivien D, Orset C, Parks WC, et al: Matrix metalloproteinase-10 effectively reduces infarct size in experimental stroke by enhancing fibrinolysis via a thrombin-activatable fibrinolysis inhibitor-mediated mechanism. Circulation 2011; 124:2909-2919.

43 Thibert KA, Raymond GV, Nascene DR Miller WP, Tolar J, Orchard PJ, et al: Cerebrospinal fluid matrix metalloproteinases are elevated in cerebral adrenoleukodystrophy and correlate with MRI severity and neurologic dysfunction. PloS One 2012;7:e50430.

44 Elvsåshagen T, Moberget T, Bøen E, Boye B, Englin NOA, Pedersen PØ, et al: Evidence for impaired neocortical synaptic plasticity in bipolar II disorder. Biol Psychiatry 2012;71:6874.

45 Femenía T, Gómez-Galán M, Lindskog M, Magara S: Dysfunctional hippocampal activity affects emotion and cognition in mood disorders. Brain Res 2012;1476:58-70.

46 Garaschuk O: Imaging microcircuit function in healthy and diseased brain. Exp Neurol 2013;242:41-49.

47 Wake H, Moorhouse AJ, Nabekura J: Functions of microglia in the central nervous system - beyond the immune response. Neuron Glia Biol 2011;7:47-53.

48 Graeber MB, Li W, Rodriguez ML: Role of microglia in CNS inflammation. FEBS Lett 2011; 585:3798-3805.

$\checkmark 49$ Beumer W, Gibney SM, Drexhage RC, PontLezica L, Doorduin J, Klein HC, et al: The immune theory of psychiatric diseases: a key role for activated microglia and circulating monocytes. J Leukoc Biol 2012;92:959-975.

50 Stertz L, Magalhães PVS, Kapczinski F: Is bipolar disorder an inflammatory condition? The relevance of microglial activation. Curr Opin Psychiatry 2013;26:19-26.

51 Paradise MB, Naismith SL, Norrie LM, Graeber MB, Hickie IB: The role of glia in late-life depression. Int Psychogeriatrics 2012;24: 1878-1890.

52 Tunis SL, Johnstone BM, Kinon BJ, Barber BL, Browne RA: Designing naturalistic prospective studies of economic and effectiveness outcomes associated with novel antipsychotic therapies. Value Health 2000;3:232-242.

53 Sullivan PF: Spurious genetic associations. Biol Psychiatry 2007;61:1121-1126. 